\title{
Remote Sounding of Multilayer Cirrus Cloud Systems Using AVHRR Data Collected during FIRE-II-IFO
}

\author{
S. C. Ou AND K. N. LiOu \\ Department of Atmospheric Sciences, University of California, Los Angeles, Los Angeles, California \\ T. R. CAUDILL \\ Division of Atmospheric Science, Geophysics Directorate, Phillips Laboratory, Hanscom Air Force Base, Massachussetts
}

(Manuscript received 25 November 1996, in final form 5 August 1997)

ABSTRACT

\begin{abstract}
Surface observations show that multilayer clouds frequently occur in frontal areas where cirrus clouds overlie boundary layer convective clouds or stratus clouds. In this paper, an algorithm is presented for the retrieval of cirrus cloud optical depths and ice crystal sizes in multilayer cloud systems based on the theory of radiative transfer and parameterizations. For the validation of the retrieval program, AVHRR data is analyzed for two dates during FIRE-II-IFO in which cirrus clouds overlie a layer of low stratus cloud. It is shown that the domainaveraged retrieved cloud temperatures are within the boundaries of cirrus clouds determined from the collocated replicator, radar, and lidar data. The retrieved ice crystal mean effective sizes and optical depths are also in general agreement with the values determined from the balloon-borne replicator and 2D probe data.
\end{abstract}

\section{Introduction}

Most of the satellite cirrus cloud retrieval programs have been designed primarily for applications to a single-layer system. Aircraft and surface observations, however, show that multilayer clouds frequently occur in frontal areas where cirrus clouds overlie boundary layer convective clouds or stratus clouds (Fye 1978; Hahn et al. 1982, 1984; Tian and Curry 1989). In particular, the former two papers show that the probability of cirrus clouds overlying low stratus or altostratus clouds is higher than $50 \%$. Similar observational statistics were obtained by Mace (1997) based on the 94$\mathrm{GHz}$ radar returns data. During a number of field experiments (FIRE-I, Wisconsin, October-November 1986; FIRE-II-Cirrus, Kansas, November-December, 1991; UAV-ARESE, northern Oklahoma, SeptemberOctober 1995; SUCCESS, Kansas, April-May 1996), multiple cloud layers involving cirrus overlying lowerlevel clouds also occurred in many cases. Application of a single-layer satellite retrieval algorithm to multilayer conditions can produce erroneous results.

To study multilayer cirrus cloud systems using satellite data, Baum et al. $(1994,1995)$ applied the $\mathrm{CO}_{2}$ slicing method to the HIRS data for the determination

Corresponding author address: Department of Atmospheric Sciences, University of California, Los Angeles, 405 Hilgard Ave., Los Angeles, CA 90095.

E-mail: ssou@atmos.ucla.edu of cirrus cloud heights and effective emissivities. Their results have been verified using 10.6- $\mu \mathrm{m}$ lidar and 94$\mathrm{GHz}$ radar measurements. Recently, Ou et al. (1996) developed a numerical scheme to identify multilayer cirrus cloud systems using AVHRR data. It is based on the physical properties of the AVHRR $0.63-\mu \mathrm{m}$ reflectances, $0.63-0.86-\mu \mathrm{m}$ reflectance ratios, the 10.9-12.0$\mu \mathrm{m}$ brightness temperature differences, and the 10.9$\mu \mathrm{m}$ brightness temperatures. In this scheme, clear pixels are first separated from cloudy pixels, which are then classified into three types: cirrus, cirrus-low cloud, and low clouds. The detection results have been validated against the cloudy conditions inferred from the collocated and concurrent ground-based lidar and radar images, balloon-borne replicator data, and NCAR-CLASS humidity soundings on a case-by-case basis. In every case, the satellite detection results are consistent with the cloudy conditions inferred from these independent and complementary measurements.

In this paper, we present in section 2 an algorithm for the retrieval of optical depths and ice crystal sizes for cirrus clouds in multilayer cloud systems based on the theory of radiative transfer and parameterizations. In section 3, we analyze the satellite data for two dates (28 and 29 November 1991) during FIRE-II-IFO, in which cirrus clouds overlay a layer of low stratus clouds and compare the retrieval results with those determined from the balloon-borne replicator and 2D probe data. Summary and conclusions are given in section 4 . 


\section{Retrieval algorithm}

Retrieval of the cirrus cloud optical depth and ice crystal size in multilayer cirrus conditions using the AVHRR 0.63-, 3.7-, and 10.9- $\mu \mathrm{m}$ channels follows the numerical procedures developed by Ou et al. (1993), Rao et al. (1995), and Ou et al. (1995). In brief, the 3.7- and $10.9-\mu \mathrm{m}$ thermal radiances are used to retrieve the cloud temperature and emissivity from which the ice crystal size and optical depth can be determined on the basis of cloud microphysics and radiative transfer parameterizations. Removal of the solar component in the 3.7- $\mu \mathrm{m}$ radiance for applications to daytime satellite data is then made by correlating the $3.7-\mu \mathrm{m}$ (solar) and $0.63-\mu \mathrm{m}$ reflectances. We have used in the algorithm development a representative cirrus model consisting of $50 \%$ bullet rosettes, $30 \%$ hollow columns, and $20 \%$ plates. The assumptions and limitations implicit in this retrieval-removal scheme have been discussed in the aforementioned references. Validation of the algorithm has been performed by using various datasets that were collected during FIRE-II-IFO.

We have modified the preceding retrieval program to include the presence of low cloud. The 3.7- and 10.9$\mu \mathrm{m}$ upwelling radiances reaching the cirrus cloud base is approximated by the upwelling radiances at the top of the atmosphere for a neighboring low-cloud pixel because very little water vapor is present above the upper-cirrus cloud deck. In this manner, we assume that the region above the cirrus cloud is totally transparent and that the radiative properties of the neighboring lowcloud pixel are representative of those of the low cloud underneath the cirrus. In practice, the retrieval area is divided into a number of scenes $\left(1.0^{\circ} \times 1.0^{\circ}\right)$. The multilayer detection scheme developed by $\mathrm{Ou}$ et al. (1996) is applied to the satellite data covering the scenes. If the area coverage of low-cloud pixels is larger than the overlying cirrus within a scene, then the upwelling radiances reaching the cirrus cloud base can be determined from the statistical histogram analyses for low-cloud radiances similar to the single-layer cirrus case (Ou et al. 1993). However, if both cirrus and low clouds have the same coverage, information of the thermal upwelling radiances in the 3.7- and 10.9- $\mu \mathrm{m}$ channels is unknown and must be assumed a priori. Retrieval of the cirrus cloud parameters can subsequently be carried out utilizing existing algorithms.

Sensitivity studies on the effects of cirrus cloud height and ice crystal sizes on the upwelling radiances have been carried out in our previous works (Ou et al. 1993). Here, we have studied the effects of low-cloud top height on the upwelling radiances. Figures $1 \mathrm{a}-\mathrm{c}$ show the correlations of simulated 3.7- $\mu \mathrm{m}$ (channel 3) and $10.9-\mu \mathrm{m}$ (channel 4) radiances for cirrus clouds at $9 \mathrm{~km}$ overlapping thermally black low clouds at 2,4 , and 6 $\mathrm{km}$, respectively. These correlation curves are obtained based on radiative transfer parameterizations (Ou et al. 1993). The solid curve represents the correlation of the
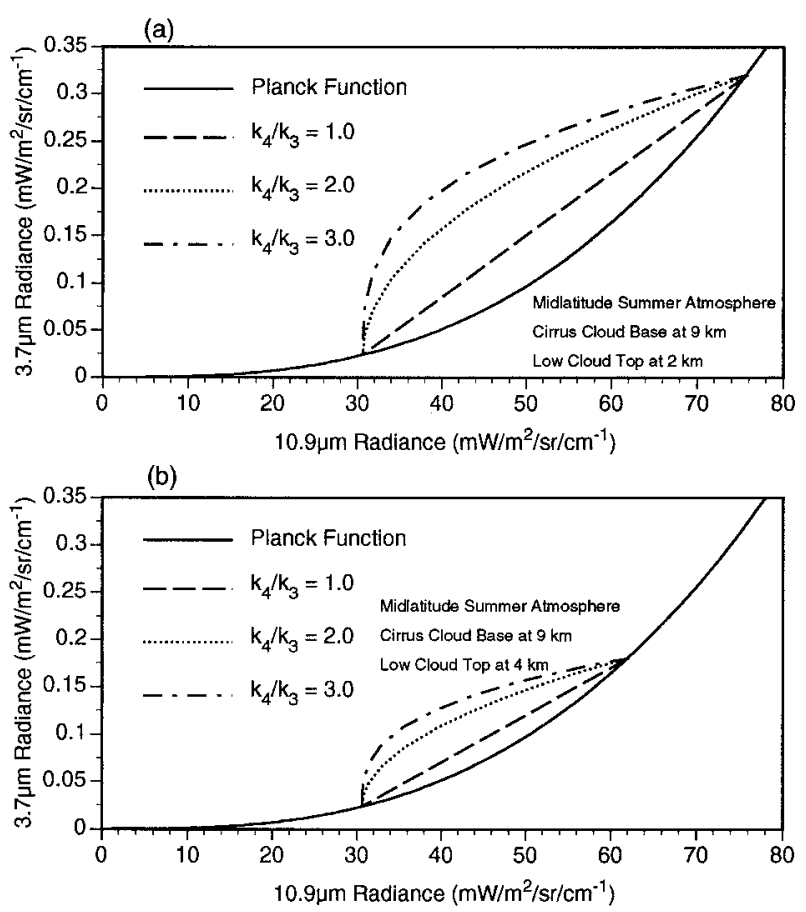

(c)

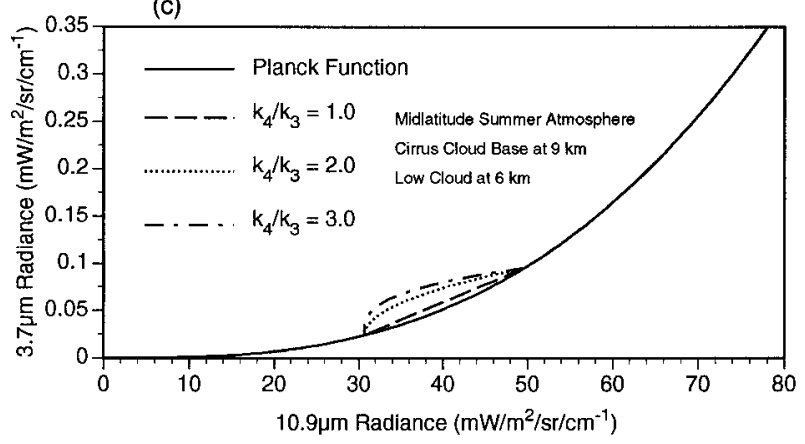

FIG. 1. Correlations of the computed channels 3 and 4 radiances that are based on radiative transfer parameterizations (Ou et al. 1993) for three values of $k_{4} / k_{3}$ along with the Planck function curve. The low cloud radiances are obtained for cloud top heights at (a) 2, (b) 4 , and (c) $6 \mathrm{~km}$. The cirrus cloud base is fixed at $9 \mathrm{~km}$.

Planck functions for both channels. In each frame, the three correlation curves above the Planck function curve are obtained for three different extinction ratios $k_{4} / k_{3}$ (Ou et al. 1993) for cirrus clouds. The upper convergence point is associated with the low-cloud radiance, and the lower intersection between the correlation curves and the Planck function curve denotes the Planck function of cirrus cloud temperature. The curvature of the correlation curves increases with increasing values of the extinction ratio. Associated with the change of the extinction ratio from 1.0 to 3.0, the largest shifts in the 3.7- $\mu \mathrm{m}$ radiances are approximately $0.2,0.1$, and $0.05 \mathrm{~mW}\left(\mathrm{~m}^{2} \mathrm{sr} \mathrm{cm}^{-1}\right)^{-1}$ for low clouds at 2, 4, and 6 $\mathrm{km}$, respectively. Because the extinction ratio is a function of ice crystal size distribution, this decrease of the largest change of the 3.7- $\mu \mathrm{m}$ radiances with increasing 

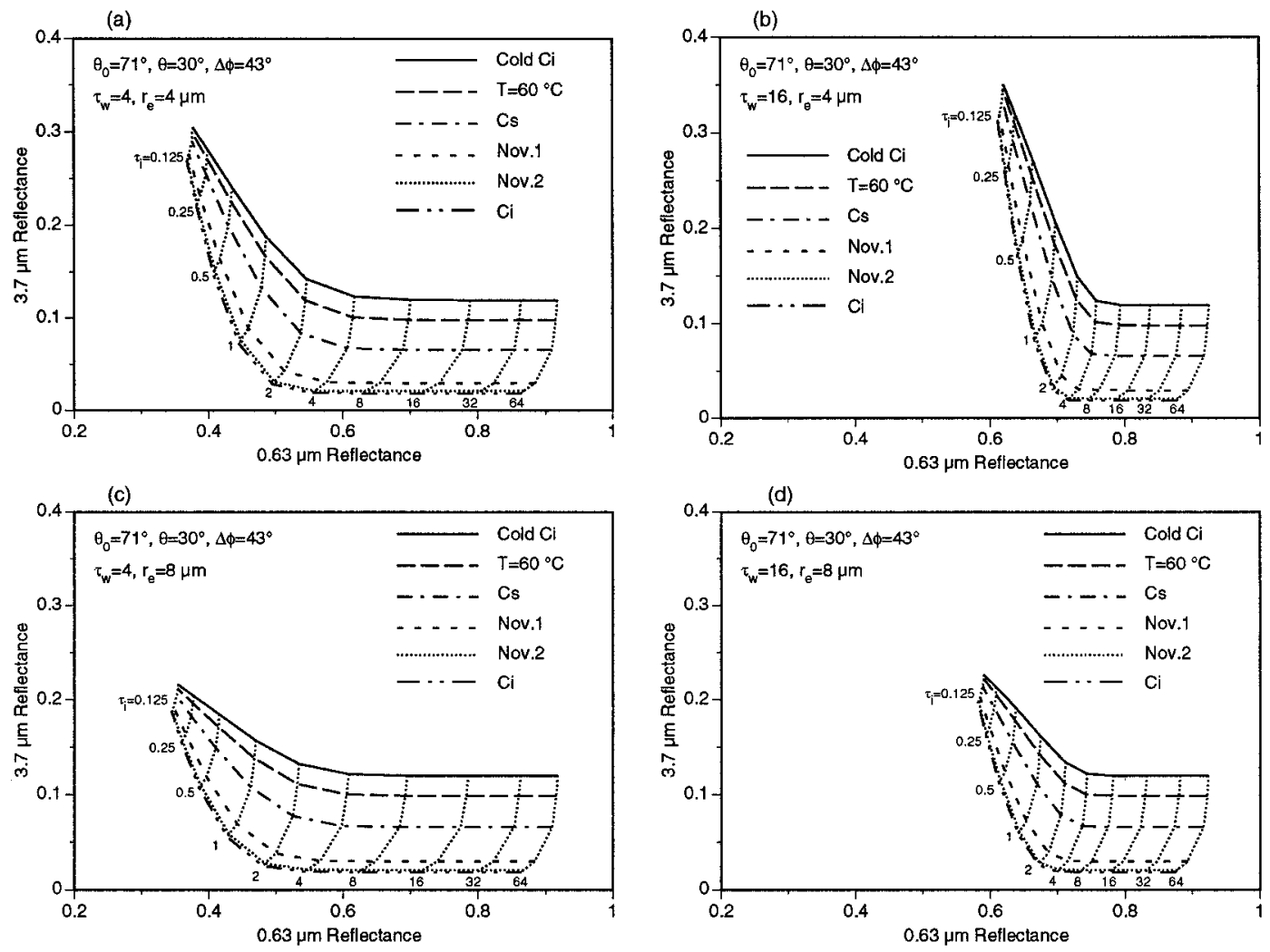

FIG. 2. Correlations between the channel 3 solar reflectance and channel 1 reflectance based on radiative transfer parameterizations (Rao et al. 1995) for six measured ice crystal size distributions. The low-cloud reflectances are obtained for four sets of optical depths $\tau_{w}$ and droplet radius $r_{e}$ : (a) $\tau_{w}=4, r_{e}=4 \mu \mathrm{m}$; (b) $\tau_{w}=16, r_{e},=4 \mu \mathrm{m}$; (c) $\tau_{w}=4$, $r_{e}=8 \mu \mathrm{m}$; and (d) $\tau_{w}=16, r_{e}=8 \mu \mathrm{m}$.

low-cloud height indicates that the $3.7-\mu \mathrm{m}$ radiance is less sensitive to ice crystal size if the underlying low cloud is located at a higher altitude. Moreover, the difference between the $10.9-\mu \mathrm{m}$ low-cloud radiance and the 10.9- $\mu \mathrm{m}$ Planck function of cirrus cloud temperature becomes smaller for increasing low-cloud height, indicating that the $10.9-\mu \mathrm{m}$ radiance is also less sensitive to the cirrus optical depth as the low cloud becomes higher. The preceding analyses imply that the uncertainty in the retrieval of cirrus cloud optical depth and ice crystal size will grow if the cirrus clouds and the low clouds come closer to each other. Thus, it will be more difficult to retrieve cirrus cloud parameters for the case of cirrus overlapping altostratus than for the case of cirrus overlying low-level stratus.

To remove the 3.7- $\mu \mathrm{m}$ solar component, we use the parametric equation for the bidirectional reflectance [Eq. (1), Rao et al. 1995)], in which the 0.63- and 3.7- $\mu \mathrm{m}$ effective surface albedos are replaced by the low-cloud albedos of the corresponding channels. The $0.63-\mu \mathrm{m}$ low-cloud albedo can be determined from the statistical analyses of radiances for low-cloud pixels. In the case when limited low-cloud pixels are detected within the selected scene, the climatological microphysics data for stratus are used to perform theoretical calculations to obtain the $0.63-\mu \mathrm{m}$ low-cloud albedo. Overall, for a cirrus optical depth larger than 1 , the maximum removal error due to reasonable uncertainties in low-cloud albedo is less than $12 \%$ (Rao et al. 1995). The procedures for determining the 3.7- $\mu \mathrm{m}$ low-cloud albedo from radiative transfer calculations are described as follows. Assuming that low clouds are composed of water droplets, we construct a look-up correlation table relating the 3.7- $\mu \mathrm{m}$ solar reflectance to the $0.63-\mu \mathrm{m}$ reflectance for a range of droplet size distributions, using the adding-doubling method for radiative transfer (Takano and Liou 1989). The droplet size distribution is expressed in the form of the generalized gamma distribution $(\mathrm{Hu}$ and Stamnes 1993). The characteristic (referential) radius is varied to obtain the correlation for different droplet sizes. The single scattering properties are then obtained from parameterizations in terms of the effective radius based on Mie scattering computations ( $\mathrm{Hu}$ and Stamnes 1993), where the effective radius is defined as the ratio of the third moment to the second moment of the size distribution. In the computations, we use 10 optical depths ranging from 0.125 to 64 . Once the lookup correlation table is established, the 3.7- $\mu \mathrm{m}$ solar effective low-cloud albedo can be determined.

If the area coverage of low-cloud pixels is larger than 


\section{FIRE II - IFO \\ November 29, 19911400 UTC}
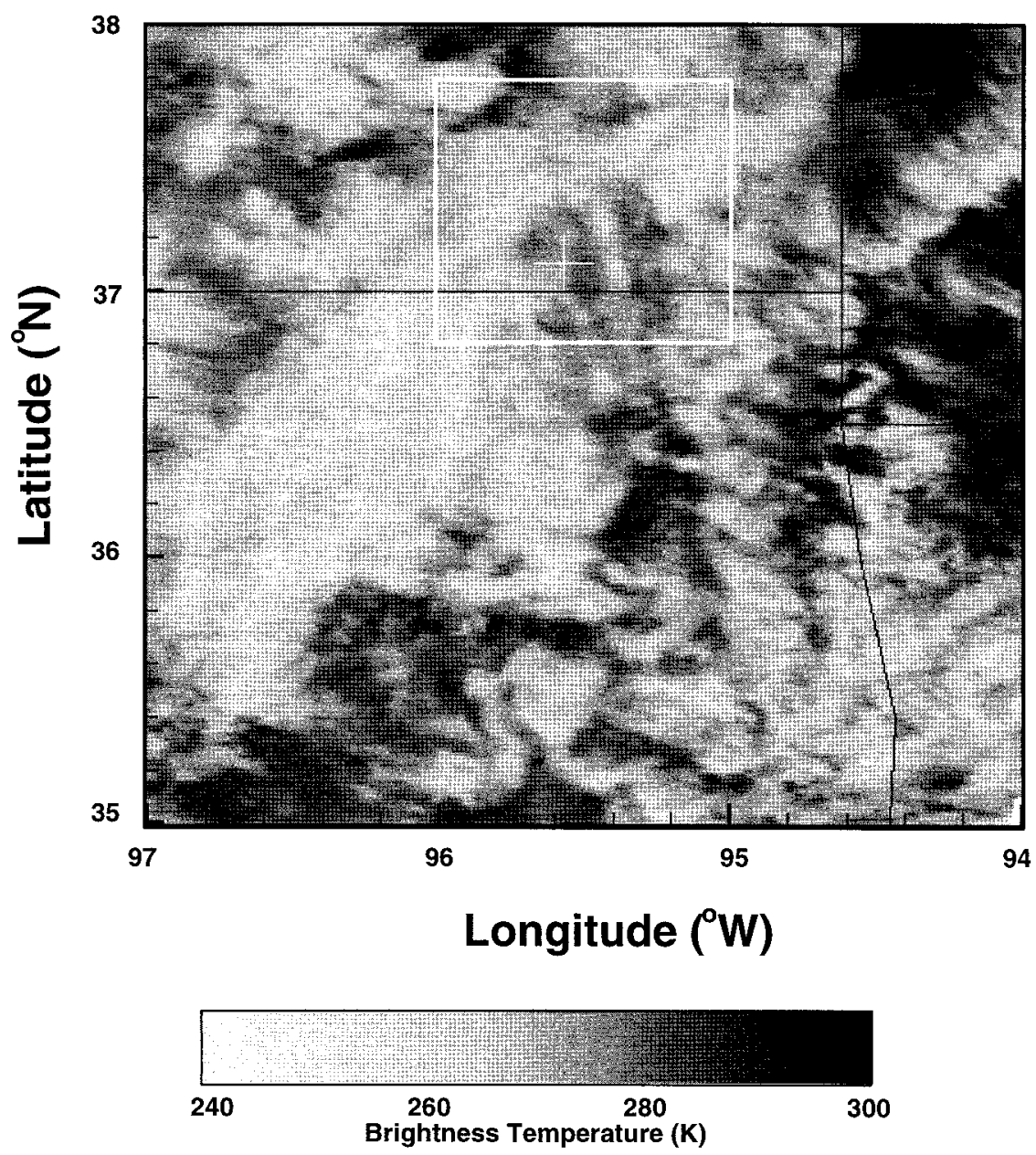

FIG. 3. Display of AVHRR channel 4 brightness temperature and the retrieved optical depth over a $3.0^{\circ} \times 3.0^{\circ}$ area around Coffeyville, Kansas (denoted by the symbol "+"), at 1400 UTC 29 November 1991 . The framed $1.0^{\circ} \times 1.0^{\circ}$ area denotes the detection and retrieval domain.

the overlying cirrus, the solar component of the $3.7-\mu \mathrm{m}$ low-cloud radiance can be obtained iteratively. Using the theoretical relationship between the 3.7-10.9- $\mu \mathrm{m}$ brightness temperature difference and the $10.9-\mu \mathrm{m}$ brightness temperature based on radiative transfer parameterizations, we can compute the initial 3.7- $\mu \mathrm{m}$ thermal IR component for a trial droplet radius. If we assume that the low cloud is optically thick (greater than 5 ), as demonstrated by the ISCCP cloud climatology (Rossow and Lacis 1990), this relationship is a function of the droplet radius only (Baum et al. 1994), and the 3.7-10.9- $\mu \mathrm{m}$ brightness temperature difference is not necessarily zero due to scattering effects. With the aid of the $0.63-\mu \mathrm{m}$ low-cloud reflectance and a trial droplet radius, an initial estimate of the solar component of the
3.7- $\mu \mathrm{m}$ low-cloud radiance is calculated. We then compare the sum of the solar and thermal components with the satellite-measured 3.7- $\mu \mathrm{m}$ radiance. If the computed radiance differs from the measured radiance, we adjust the droplet radius so as to make the computed value closer to the measured value. The process is repeated until the computed value matches the measured value, and the $3.7-\mu \mathrm{m}$ low-cloud albedo is obtained from the resulting 3.7- $\mu \mathrm{m}$ solar component. If both the cirrus and low clouds have the same coverage, the droplet radius is prescribed as $8 \mu \mathrm{m}$.

Sensitivity studies on the effects of uncertainties in ice crystal size and the low cloud/surface albedo have been performed by Rao et al. (1995). Here, in a similar manner, we have also studied the sensitivity of the 3.7- 


\section{FIRE-II-IFO, Nov. 29, 1400UTC}


FIG. 4. Display of (a) the retrieved optical depth and (b) the retrieved mean effective ice crystal size at 1400 UTC 29 November 1991 over the retrieval domain shown in Fig. 3.

$\mu \mathrm{m}$ solar component to the variation of the effective droplet radius $r_{e}$ and low-cloud optical depth. Figures $2 \mathrm{a}-\mathrm{d}$ show four representative cases for the correlation between the AVHRR 0.63- and 3.7- $\mu \mathrm{m}$ channel reflectances for the condition of cirrus on top of low stratus. Radiative transfer calculations were performed for six ice crystal size distributions with the mean effective sizes ranging from 23.9 to $123.6 \mu \mathrm{m}$ and for four sets of the water cloud optical depth $\tau_{w}$ and droplet radius [(a) $\tau_{w}=4, r_{e}=4 \mu \mathrm{m}$; (b) $\tau_{w}=16, r_{e}=4 \mu \mathrm{m}$; (c) $\tau_{w}=4, r_{e}=8 \mu \mathrm{m}$; and (d) $\left.\tau_{w}=16, r_{e}=8 \mu \mathrm{m}\right]$ based on the prescribed sun-satellite geometry. For cirrus clouds with optical depths greater than 4 , the $3.7-\mu \mathrm{m}$ reflectances depend on ice crystal sizes only, and they are virtually independent of low-cloud properties. For cirrus clouds with optical depths less than 4, the 3.7$\mu \mathrm{m}$ reflectances are more sensitive to $r_{e}$ than to $\tau_{w}$. By comparing panels (a) and (b) and panels (c) and (d), we see that for the same cirrus cloud optical depth and ice crystal size and for the same $r_{e}$, the $3.7-\mu \mathrm{m}$ radiances are the same because the $3.7-\mu \mathrm{m}$ reflectance approaches asymptotic value for optically thick low clouds. However, by comparing panels (a) and (c) and panels (b) and (d), we see that for the same cirrus cloud optical depth and ice crystal size and for the same $\tau_{w}$, the 3.7$\mu \mathrm{m}$ radiances for smaller $r_{e}$ are larger than those for larger $r_{e}$ because the asymptotic value of 3.7- $\mu \mathrm{m}$ lowcloud reflectance depends on $r_{e}$ only. These analyses indicate that errors in the removed 3.7- $\mu \mathrm{m}$ solar component mainly result from the uncertainty in $r_{e}$. How- 
ever, according to Rao et al. (1995), for the optically thick low-cloud albedo varying between 0.05 and 0.15 , which is roughly equivalent to a $4-12-\mu \mathrm{m}$ change of $r_{e}$, the error in the removed solar component $\left(\theta_{0}=71^{\circ}\right.$, $\theta=40^{\circ}, \Delta \phi=146^{\circ}$ ) is only significant for cirrus clouds with optical depth less than 1 . For cirrus clouds with optical depth larger than 1, the removal error is less than $15 \%$. This means that fixing $r_{e}$ the present cirrus retrieval algorithm may not produce significant error for typical cirrus clouds with optical depth larger than 1.

\section{Application and validation of the cirrus cloud retrieval algorithm}

The preceding cirrus cloud retrieval scheme is applied to AVHRR-HRPT data obtained during FIRE-II-IFO. We focus on two dates: 28 and 29 November 1991. For these dates, both sounding observations and lidar backscattering measurements indicated the presence of cirrus clouds overlying overcast or broken lower stratus clouds around Coffeyville (the observation site). For validation, we have also analyzed the balloon-borne replicator data (1649 UTC 28 November and 1343 UTC 29 November) and the 2D-probe data obtained from the NCAR King Air turboprop (1754-2158 UTC 28 November). The replicator launched on 29 November and the aircraft flight on 28 November were nearly concurrent with the NOAA-12 and - 11 overpasses, respectively. The replicator launched on 28 November was between the NOAA-12 and -11 overpasses. We have followed the analytical models to compute the optical depth and ice crystal mean effective size from both the replicator and 2D-probe data developed by Ou et al. (1995) for validation of the retrieved results. The mean effective size has been defined as the mean width weighted by the cross section of ice crystals (Ou et al. 1993; Ou et al. 1995).

\section{a. The 29 November case}

The weather synopsis for this date has been given in Ou et al. (1996). NOAA-12 flew over Coffeyville area around 1400 UTC during which both the image of 94$\mathrm{GHz}$ radar (located at Coffeyville) and the relative humidity sounding indicated the presence of low clouds between 1 and $2 \mathrm{~km}$, while the concurrent replicator data showed the existence of ice crystals between 6.2 and $9.2 \mathrm{~km}$.

Figure 3 shows the distributions of the channel 4 brightness temperatures over a $3^{\circ} \times 3^{\circ}$ domain at 1400 UTC 29 November 1991. The symbol " + " denotes the location of Coffeyville. The framed $1^{\circ} \times 1^{\circ}$ area denotes the domain where the multilayer detection and retrieval schemes are applied. Within the framed domain, the detection scheme identifies $88.2 \%$ of cirrus/low pixels, and $11.5 \%$ of cirrus pixels. The cirrus pixels are located in the northeast quadrant of the domain. They are optically thick $\left(\bar{T}_{4}<233 \mathrm{~K}\right)$, so that it is difficult to detect
FIRE-II-IFO, Nov. 29, 1991
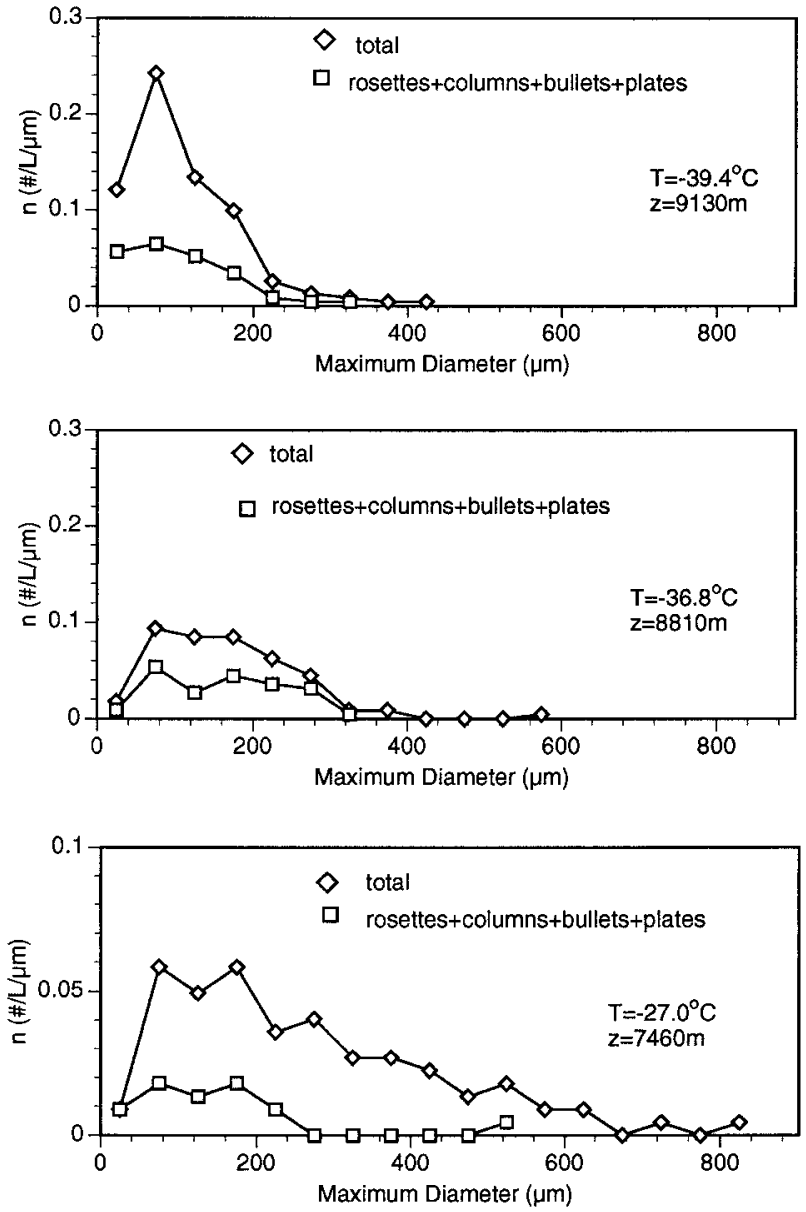

FIG. 5. Ice crystal size distributions derived from the replicator data at three selected height levels within the cloud, which was sampled between 1404 and 1414 UTC 29 November 1991.

whether low clouds exist below the cirrus for these pixels (Ou et al. 1996). Figures 4a,b show the distribution of the retrieved optical depths and mean effective sizes. The ranges of retrieved optical depths and mean effective sizes are 1-5 and 60-160 $\mu \mathrm{m}$, respectively. These values are reasonable, but their ranges indicate that cirrus clouds within the retrieval domain are far from being homogeneous.

Figures $5 \mathrm{a}-\mathrm{c}$ show the ice crystal size distributions derived from the replicator data at three selected height levels within the cirrus cloud. These ice crystal size distributions were obtained based on approximately 5s sampling of approximately 5L of cloud air. The smallest ice crystal size that can be distinctly identified is generally about $5 \mu \mathrm{m}$. Near the cloud top $(9.2 \mathrm{~km})$, the cirrus cloud is composed of relatively small hexagonal ice crystals (columns, rosettes, bullets, plates, and aggregate crystals) ranging from 25 to $425 \mu \mathrm{m}$. The ice crystal size distribution peaks at $L=75 \mu \mathrm{m}$ with a concentration of about $0.24 \mathrm{~L}^{-1} \mu \mathrm{m}^{-1}$. For the middle 
FIRE-II-IFO (November 29, 1991)
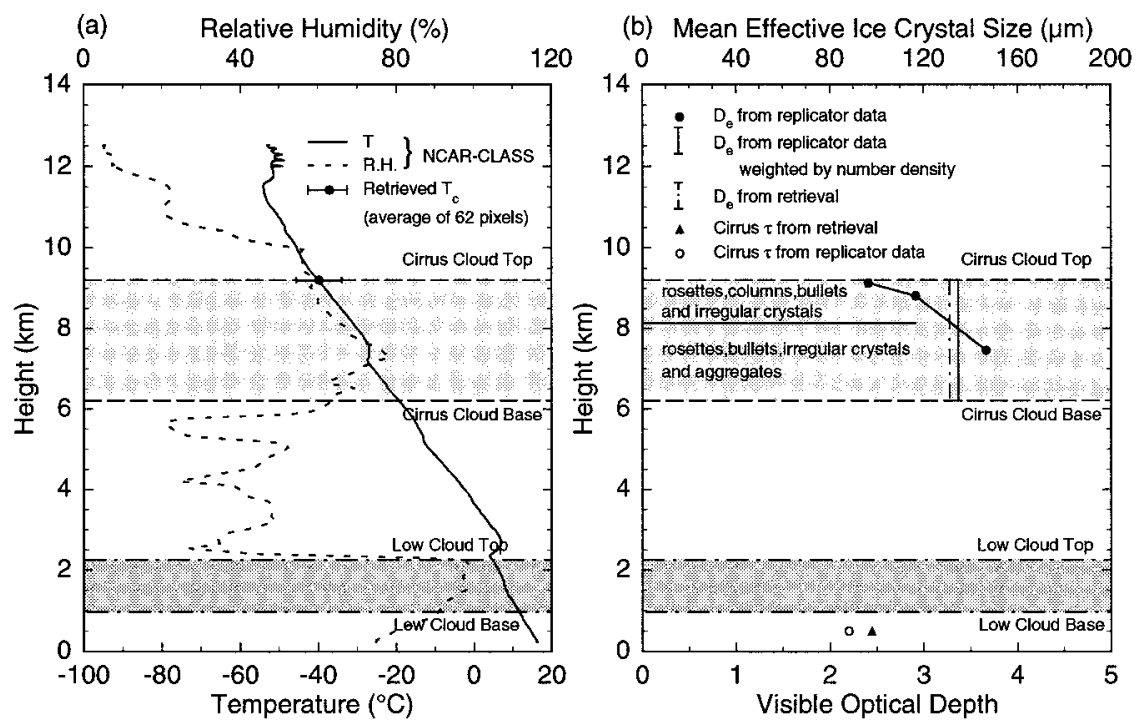

FIG. 6. (a) Cloud base and top heights for cirrus and low stratus determined from lidar, radar, and sounding data, as well as temperature and humidity profiles obtained from the NCAR CLASS sounding system at 1343 UTC 29 November 1991. Overlapped with the temperature profile are the mean retrieved cirrus cloud temperature over a $0.1^{\circ} \times 0.1^{\circ}$ domain around Coffeyville, Kansas, and (b) display of the replicator-derived mean effective sizes at selected height levels, their vertical average, and the retrieved value. Also shown on the bottom scale are the optical depths derived from the replicator data and from the retrieval.

level at $8.18 \mathrm{~km}$, the ice crystal distribution is also composed of hexagonal and irregular ice crystals with a broader size range $(25-575 \mu \mathrm{m})$. The size distribution also peaks at $75 \mu \mathrm{m}$ but with a smaller value of number concentration of $0.1 \mathrm{~L}^{-1} \mu \mathrm{m}^{-1}$. Finally, for the lowest level $(7.46 \mathrm{~km})$, the ice crystal size distribution ranges between 25 and $875 \mu \mathrm{m}$ with a peak concentration of about $0.05 \mathrm{~L}^{-1} \mu \mathrm{m}^{-1}$. It is clear that ice crystal size distributions become broader toward lower altitudes or warmer temperatures.

Because clouds are horizontally inhomogeneous, collocation and coincidence of the satellite data and replicator measurements in a Lagrangian sense are required for an adequate validation of the retrieval results. This is accomplished following the procedures described in Ou et al. (1995). Using the cloud-level wind speed and wind direction data recorded by the NCAR CLASS sounding system, we determine that at the time of satellite overpass, the cloud associated with the replicator sampling was located at a position of $37.3^{\circ} \mathrm{N}, 95.5^{\circ} \mathrm{W}$, or about $23 \mathrm{~km}$ northeast of Coffeyville. This point near Coffeyville was upwind of the sounder positions at the cloud base and top because the satellite overpass occurred before the replicator sounding. Since the coordinates of this point are subject to uncertainties in wind data, and to account for the possibility that the shear across the depth of the cloud may affect the vertical coherence over the period of interest, an area of $0.1^{\circ} \times$ $0.1^{\circ}$ around this point is subsequently selected for the verification study.
Figure 6a displays the temperature and relative humidity profiles obtained from the NCAR CLASS sounding launched at 1343 UTC. The cirrus cloud base and top heights derived from the replicator, $94-\mathrm{GHz}$ cloud radar, and visible lidar were approximately $6.2\left(-20^{\circ} \mathrm{C}\right)$ and $9.2 \mathrm{~km}\left(-41^{\circ} \mathrm{C}\right)$, respectively. A moist layer roughly corresponding to the cirrus cloud layer was evident. The RH values associated with this moist layer are below ice saturation, but their accuracies are highly uncertain and questionable. Heymsfield and Miloshevich (1993) show that in four FIRE-II-IFO cases, in situ RH values from cryogenic hygrometer are either ice supersaturated or close to ice saturation within cirrus clouds. Moreover, another moist layer $(\mathrm{RH}>90 \%)$ existed between approximately 1 and $2 \mathrm{~km}$, corresponding to a low-level cloud layer detected by the PSU radar. Temperature inversion occurred at the low-level cloud top and near the peak of the relative humidity around $7 \mathrm{~km}$. The mean retrieved cloud temperature is $233 \mathrm{~K}$, which is the average of 62 pixels within the $0.1^{\circ} \times 0.1^{\circ}$ area. The standard deviation is $5.8 \mathrm{~K}$, indicating that cloud temperatures were not uniform within the retrieval domain. Moreover, the mean cloud height determined from the temperature sounding is $9.2 \mathrm{~km}$, which is near the cloud top. Figure $6 \mathrm{~b}$ shows the vertical distribution of mean effective ice crystal sizes computed from the replicator data. The mean effective sizes for the three levels derived from replicator sounding are 96, 116, and $146 \mu \mathrm{m}$ from top to bottom. The vertically averaged mean effective ice crystal size is $134.6 \mu \mathrm{m}$ (solid ver- 


\section{FIRE II - IFO \\ November 28, 19911400 UTC}
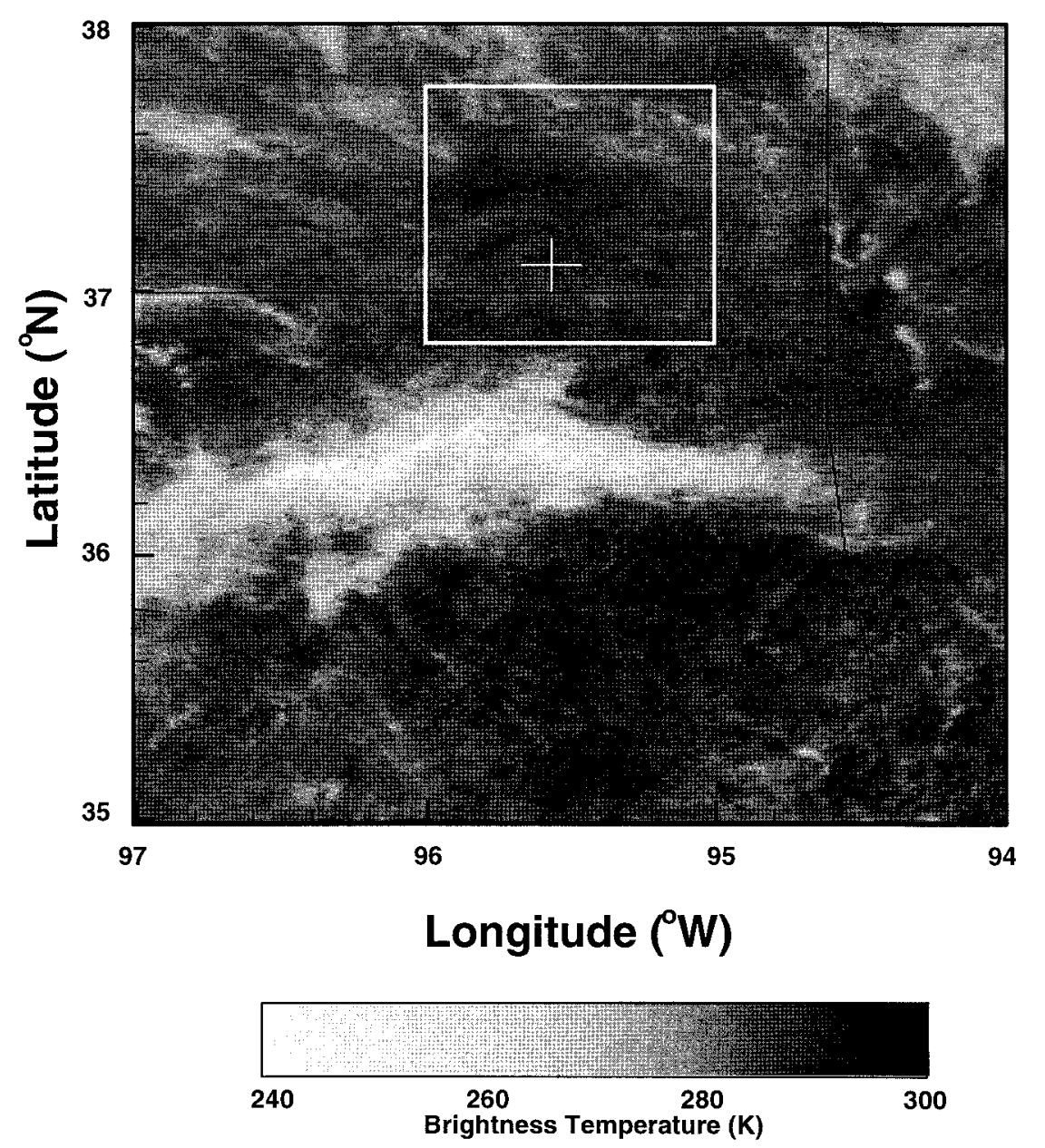

FIG. 7. Display of AVHRR channel 4 brightness temperature over a $3.0^{\circ} \times 3.0^{\circ}$ area around Coffeyville, Kansas (denoted by the symbol "+”), at 1400 UTC 28 November 1991. The framed $1.0^{\circ} \times 1.0^{\circ}$ area denotes the detection and retrieval domain.

tical bar in Fig. 6b). The retrieved mean effective size from satellite radiances is $130 \mu \mathrm{m}$, which differs from the replicator-derived value by about $5 \mu \mathrm{m}$. On the bottom scale of Fig. $6 \mathrm{~b}$ are shown the replicator-derived and the satellite-retrieved optical depths, which are 2.2 and 2.4, respectively. Reasonable agreements between the retrieved and in situ measured cirrus cloud properties are evident from these comparisons.

\section{b. The 28 November case}

The weather synopsis for this date has also been given in $\mathrm{Ou}$ et al. (1996). NOAA-12 and -11 flew over the Coffeyville area around 1421 and 2048 UTC, respectively. From 1330 to 1530 UTC, the $94-\mathrm{GHz}$ radar ech- oes revealed the presence of sparse cirrus clouds between 8 and $11 \mathrm{~km}$. Between 0 and $1 \mathrm{~km}$, the radar echoes are barely above the minimum detectable level $(\sim-60 \mathrm{dBZ})$, indicating the presence of a low cloud. The 10.6- $\mu \mathrm{m}$ lidar (located at Coffeyville) picked up cirrus signals between 10 and $12 \mathrm{~km}$ from 1415 to 1425 UTC. These cirrus clouds were not detected by the 94$\mathrm{GHz}$ radar, however, possibly because the cirrus clouds were composed of small ice crystals with small optical depth. The minimum detection threshold of the radar at cirrus altitude is also higher than at the surface. The $0.53-\mu \mathrm{m}$ lidar (deployed at Parsons, about 30 miles northeast of Coffeyville) registered cirrus clouds between 8 and $11 \mathrm{~km}$ from 1500 to 1600 UTC (Baum et al. 1995). The humidity sounding showed a moist layer 


\section{FIRE-II-IFO, Nov. 28, 1400UTC}
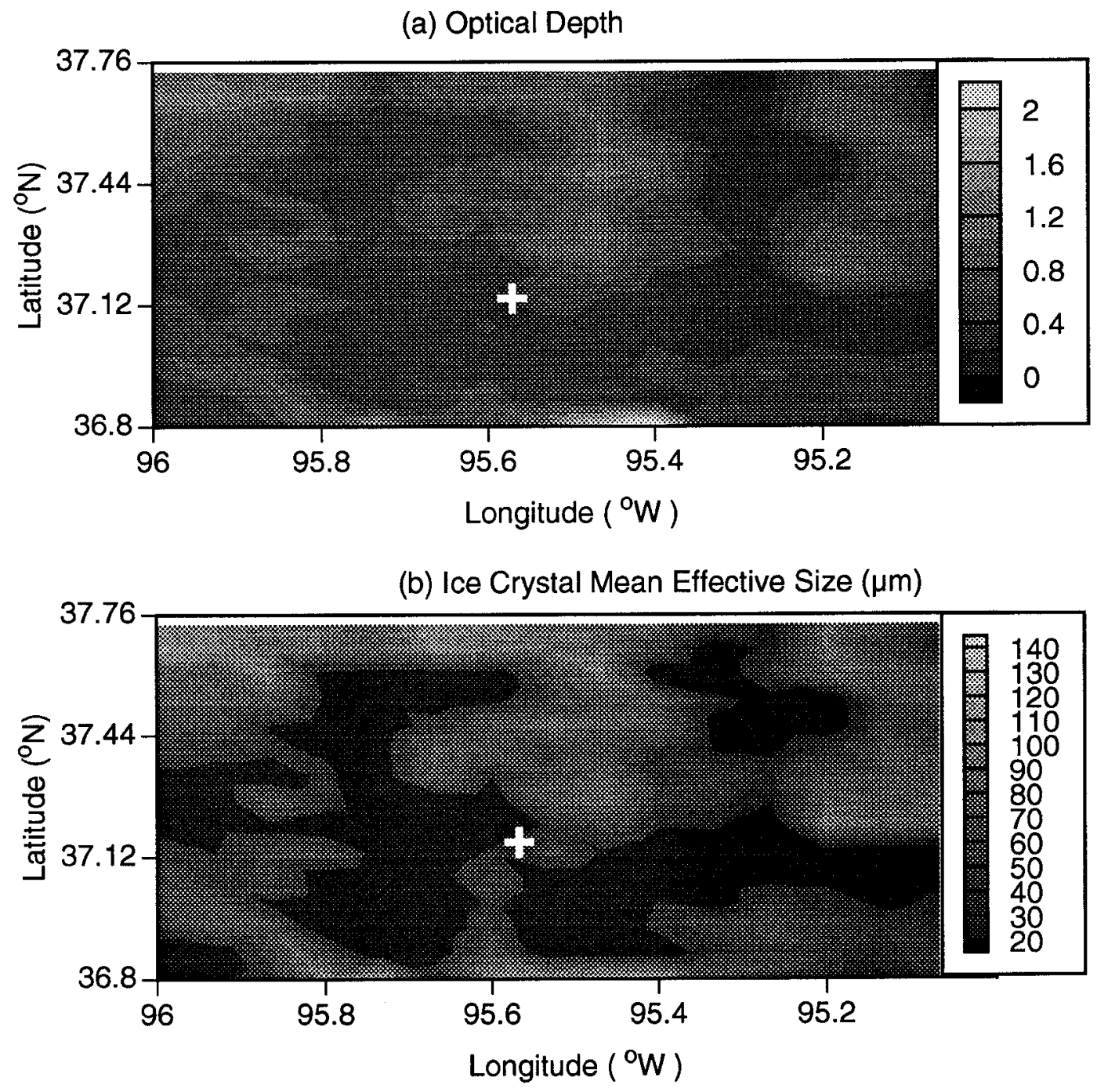

FIG. 8. Display of (a) the retrieved optical depth and (b) the retrieved mean effective ice crystal size at 1400 UTC 28 November 1991 over the retrieval domain shown in Fig. 7.

with relative humidity close to $90 \%$ between 0.5 and $1.5 \mathrm{~km}$.

From 1900 to 2300 UTC, the $94-\mathrm{GHz}$ radar detected the on-and-off presence of cirrus between 8 and $10 \mathrm{~km}$. The $94-\mathrm{GHz}$ radar did not record any low clouds because signals associated with altitudes lower than 7.5 $\mathrm{km}$ were discarded. The $10.6-\mu \mathrm{m}$ lidar image between 2034 and 2044 UTC showed the presence of broken cirrus clouds located between 8 and $9 \mathrm{~km}$. There were three broken periods caused by the blocking out of lidar signals due to the presence of optically thick low clouds above $2 \mathrm{~km}$ from 1900 to 2400 UTC. The cloud-top heights detected by the $0.53-\mu \mathrm{m}$ lidar were higher than those detected by the $94-\mathrm{GHz}$ radar and the $10.6-\mu \mathrm{m}$ lidar. The selected $1^{\circ} \times 1^{\circ}$ area around Coffeyville was identified to be containing $13.3 \%$ cirrus/low-cloud pixels, and $85.1 \%$ cirrus cloud pixels. The absence of low clouds over a large fraction of the selected domain determined from the detection scheme is supported by the fact that the relative humidity sounding in the lower troposphere is well below the saturation value.

Figures $7 \mathrm{a}-\mathrm{c}$ show the distributions of the channel 4 brightness temperatures over a $3^{\circ} \times 3^{\circ}$ domain at 1400 UTC 28 November 1991. The area was characterized by overcast cirrus clouds. As in Fig. 3, the framed $1^{\circ}$ $\times 1^{\circ}$ area denotes where the multilayer detection and 


\section{Temperature and Relative Humidity}

Nov. $28,1991: 14: 21: 13$

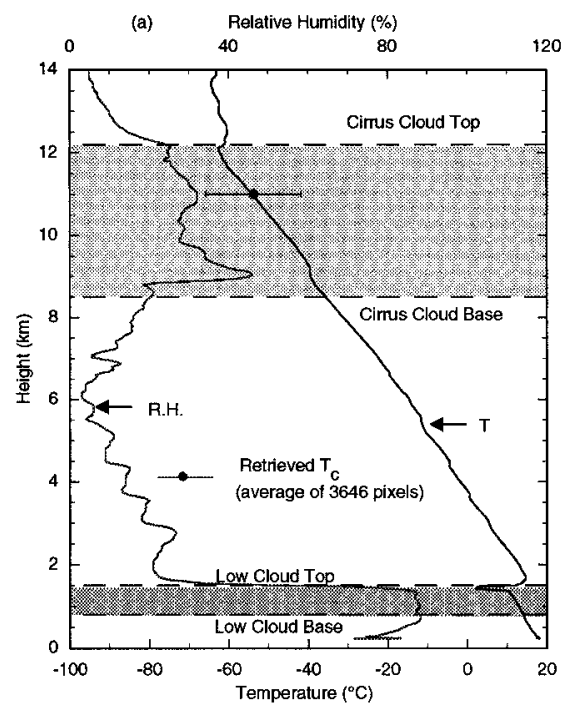

Nov. 28, 1991:20:35:58

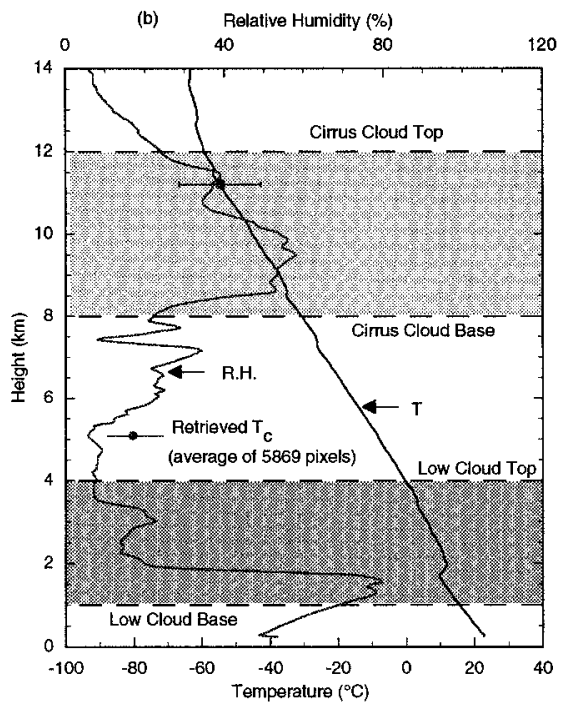

FIG. 9. Temperature and humidity profiles from NCAR CLASS soundings for (a) 1421 UTC and (b) 2035 UTC 28 November 1991. In both cases, cirrus clouds and low stratus clouds were present simultaneously. Their positions were derived from the frequency histograms of cloudiness from the $94-\mathrm{GHz}$ radar and 10.6- $\mu \mathrm{m}$ lidar measurements. Overlapped with the temperature profiles are the mean retrieved cloud temperatures over a $1^{\circ} \times 1^{\circ}$ area around Coffeyville.

retrieval schemes are applied, and the symbol "+" denotes the location of Coffeyville. The framed area was identified by the detection scheme to be containing 91.7\% cirrus/low-cloud pixels and $8.3 \%$ cirrus cloud pixels. The cirrus pixels are located to the north and southwest of Coffeyville, corresponding to regions of higher brightness temperatures. Figures $8 \mathrm{a}, \mathrm{b}$ show the distribution of the retrieved optical depths and mean effective sizes, which are on the order of 0 to approximately 2 and 20 to approximately $140 \mu \mathrm{m}$, respectively. The retrieval results for the same $1^{\circ} \times 1^{\circ}$ domain at 2100 UTC are similar, having similar optical depths and mean effective sizes. Note that these values are smaller than those shown in Fig. 4.

To confirm that the retrieved cloud temperatures are between values at the cloud top and base, we employ the statistics of cirrus cloud heights derived from the measurements of the $94-\mathrm{GHz}$ radar and 10.6- $\mu \mathrm{m}$ lidar. Figures 9a,b show the temperature and relative humidity profiles obtained from the NCAR CLASS sounding launched at 1421 and 2036 UTC, respectively. The cirrus clouds were located at $8.5-12.2 \mathrm{~km}\left(-40^{\circ}\right.$ to $\left.-60^{\circ} \mathrm{C}\right)$ and $8-12 \mathrm{~km}\left(-35^{\circ}\right.$ to $\left.-60^{\circ} \mathrm{C}\right)$. These cloud boundary parameters were maximum and minimum values derived from the frequency histograms of cloudiness as functions of altitude over the two 6-h periods (12001800 UTC and 1800-2400 UTC) for the 94-GHz radar and 10.6- $\mu \mathrm{m}$ lidar (Baum et al. 1995). Both humidity soundings showed a moist layer corresponding to the boundaries of the cirrus cloud layer, in support of the radar and lidar measurements. For the case of 1400 UTC, low clouds were located at approximately 1-1.5 $\mathrm{km}$ based on the presence of a near-saturation moist layer in the relative humidity sounding. For the case of 2100 UTC, although the humidity sounding indicated that the maximum relative humidity within the low-level moist layer was less than $80 \%$, the radar and lidar returns indicated low clouds are present between 1 and $4 \mathrm{~km}$.

Retrievals are performed over the $1^{\circ} \times 1^{\circ}$ area around Coffeyville. The cirrus-level wind speed was $39 \mathrm{~m} \mathrm{~s}^{-1}$. Thus, the size of this domain approximately corresponded to the ground-based remote sensing measurements for about $1 \mathrm{~h}$. The mean retrieved cirrus cloud temperatures are $-54^{\circ} \mathrm{C}$ and $-55^{\circ} \mathrm{C}$, which are within the lidarand radar-derived ranges of the cloud top and base temperatures. The standard deviations of the retrieved cloud temperatures in both cases are on the order of $10^{\circ} \mathrm{C}$. The radar and lidar measurements also show large variations of the cloud boundaries up to $3 \mathrm{~km}$.

To verify the retrieved mean effective sizes and optical depths, we analyze both the balloon-borne replicator data and the 2D-probe data collected during the King Air flights. The replicator was launched at 1649 UTC, which is between the two day-time satellite overpasses. Figures $10 \mathrm{a}-\mathrm{d}$ show the ice crystal size distributions derived from the replicator data at four selected height levels within the cirrus cloud. For the two levels near the cloud top $(9.79$ and $9.72 \mathrm{~km})$, the cirrus cloud 
FIRE-II-IFO, Nov. 28, 1991
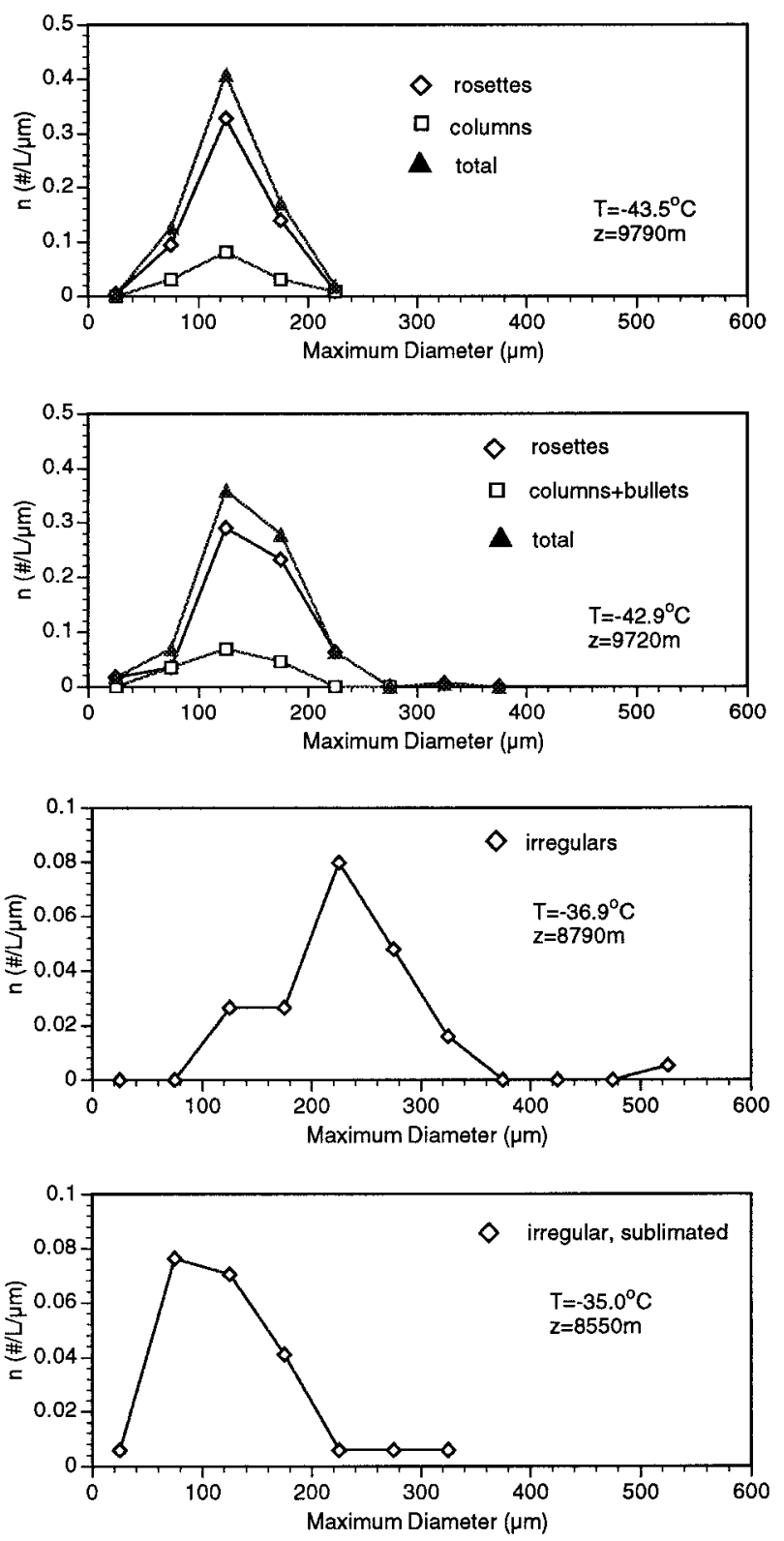

FIG. 10. Ice crystal size distributions derived from the replicator data at four selected height levels within the cloud, which was sampled between 1719 and 1724 UTC 28 November 1991.

was composed of rosettes, columns, and bullets with sizes ranging from 25 to $400 \mu \mathrm{m}$. The total ice crystal size distribution peaks at $L=125 \mu \mathrm{m}$ with a concentration of about $0.4 \mathrm{~L}^{-1} \mu \mathrm{m}^{-1}$. For the middle level at $8.79 \mathrm{~km}$, the ice crystal distribution was composed of aggregate ice crystals ranging from 25 to $525 \mu \mathrm{m}$ with the peak at $225 \mu \mathrm{m}$ and a smaller concentration of 0.08 $\mathrm{L}^{-1} \mu \mathrm{m}^{-1}$. For the lowest level $(8.55 \mathrm{~km})$, the sampled ice crystals contained aggregate and sublimated parti- cles. The size distribution ranged from 25 to $325 \mu \mathrm{m}$, peaking at $50 \mu \mathrm{m}$ with a concentration around $0.08 \mathrm{~L}^{-1}$ $\mu \mathrm{m}^{-1}$.

The cirrus cloud on 28 November was also sampled by NCAR King Air turboprop in the vicinity of Coffeyville. The flight tracks and altitudes of the aircraft as a function of time are shown in Figs. 11a,b. The period analyzed for the King Air, which included racetrack patterns at five altitudes, coincided with NOAA11 AVHRR overpass (2010 to approximately 2106 UTC). It was equipped with two PMS 2D probes, which were capable of sizing the ice crystals from $25 \mu \mathrm{m}$ to above $1.0 \mathrm{~mm}$ with $25-\mu \mathrm{m}$ increments (2D-C) and from $100 \mu \mathrm{m}$ to above $2.0 \mathrm{~mm}$ in $100-\mu \mathrm{m}$ increments (2D$\mathrm{P})$. The accuracy of the $2 \mathrm{D}-\mathrm{C}$ and $2 \mathrm{D}-\mathrm{P}$ measurements is poor at sizes less than 100 and $400 \mu \mathrm{m}$, respectively (Heymsfield and Baumgardner 1985). Ice crystals were sized into 1 of 12 bins for each $5 \mathrm{~s}$ of flight time, and for each bin concentrations were calculated. Each bin was further subdivided into 10 increments from 0.1 to 1.0 , according to the ratio of the area of the particle compared to an equivalent diameter sphere.

Following the method described by Ou et al. (1995), we analyze each 5-s average ice crystal size spectrum obtained from 2D-C probe because this probe has higher size-bin resolution than the $2 \mathrm{D}-\mathrm{P}$ probe. Figures $12 \mathrm{a}, \mathrm{b}$ show the time series of mean effective ice crystal size and extinction coefficient as functions of time for the analysis period. Note that overall, the mean effective size varies between 30 and $120 \mu \mathrm{m}$. The extinction coefficients vary between 0 and $2 \times 10^{-3} \mathrm{~m}^{-1}$, again indicating the inhomogeneous nature of cirrus clouds. Validation of the retrieved cirrus mean effective size and optical depth can only be carried out in an average sense. For each leg, we obtain the horizontally averaged mean effective size and extinction coefficient, which are then used to obtain vertically averaged mean effective size and optical depth, respectively.

Figure 13a shows the vertical distribution of mean effective size computed from the replicator data. The mean effective sizes for the four sampled levels were $65,71,126$, and $94 \mu \mathrm{m}$ with an averaged mean effective size to be $96.6 \mu \mathrm{m}$, as shown in Fig. 13a by the solid vertical bar. This value is the sum of the mean effective ice crystal size at a given level weighted by the extinction coefficient at that level normalized by the optical depth. The temporally averaged retrieved mean effective sizes for 1400 and 2100 UTC overpasses based on the $1^{\circ} \times 1^{\circ}$ retrieval domain is $86.6 \mu \mathrm{m}$. On the bottom scale of Fig. 13a are shown the replicator-derived and the satellite-retrieved optical depths, which are 0.97 and 0.86 , respectively. Although the present retrieval algorithm has been applied to a spatial domain of $1^{\circ} \times 1^{\circ}$, in contrast to the small-volume sampling of the replicator and the temporal difference between satellite overpass and replicator sampling that is on the order of $3 \mathrm{~h}$, the differences between retrieval and replicator values are nevertheless relatively small. 

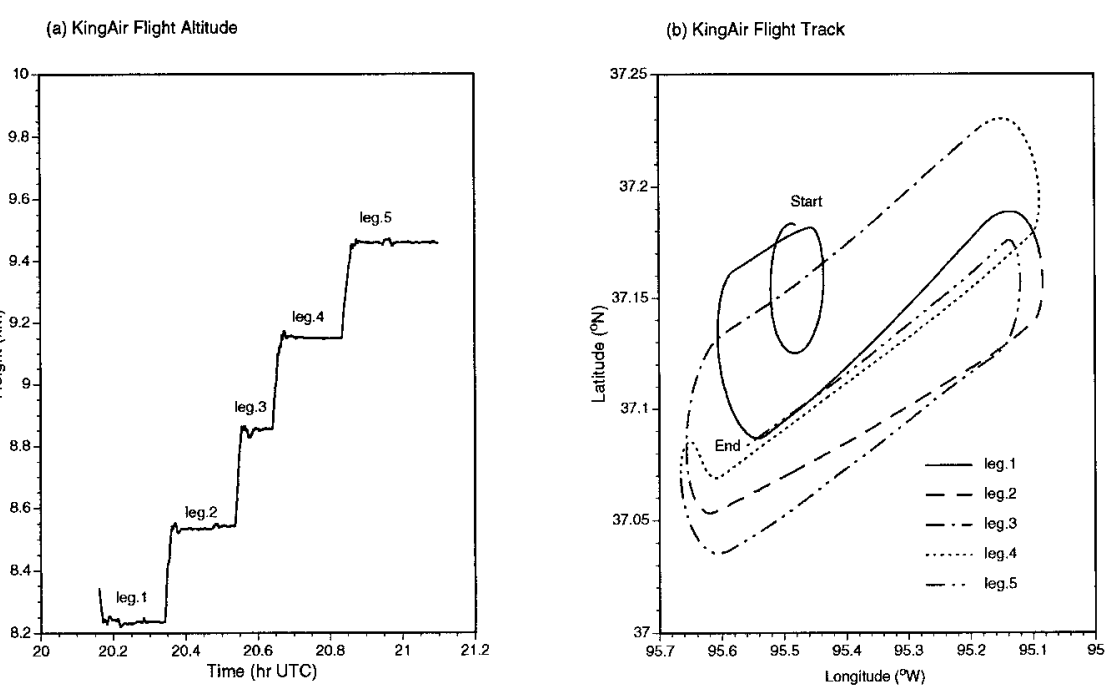

FIG. 11. The (a) flight altitude and (b) latitude-longitude of flight track of King Air for the period 2010-2106 UTC 28 November 1991.

Figure $13 \mathrm{~b}$ shows the vertical distribution of mean effective sizes computed from the $2 \mathrm{D}-\mathrm{C}$ probe data. The mean effective sizes for the five horizontal legs in the ascending order are 84.5, 92.6, 81.3, 83.1, and $80.4 \mu \mathrm{m}$. One notable feature is that the vertical variation of these values was smaller than that from the replicator data, possibly because the derived aircraft values were based on averages of the data collected over a long distance, while the replicator values were point and instantaneous observations. From the $2 \mathrm{D}-\mathrm{C}$ probe data, the vertically averaged mean effective ice crystal size is $84.3 \mu \mathrm{m}$. For the purpose of collocation, the retrieval in this particular case is performed over a rectangular area that enclosed the flight track during the analysis period. The satelliteretrieved mean effective size is $81.1 \mu \mathrm{m}$. On the bottom scale of Fig. 13b are shown the 2D-C derived and the retrieved optical depths, which are 0.66 and 0.65 , respectively. The standard deviations for the retrieval values are $22 \mu \mathrm{m}$ and 0.5 . The magnitude of the spatial variation of the retrieved cirrus cloud parameters is com-

FIRE-II-IFO (November 28,1991)
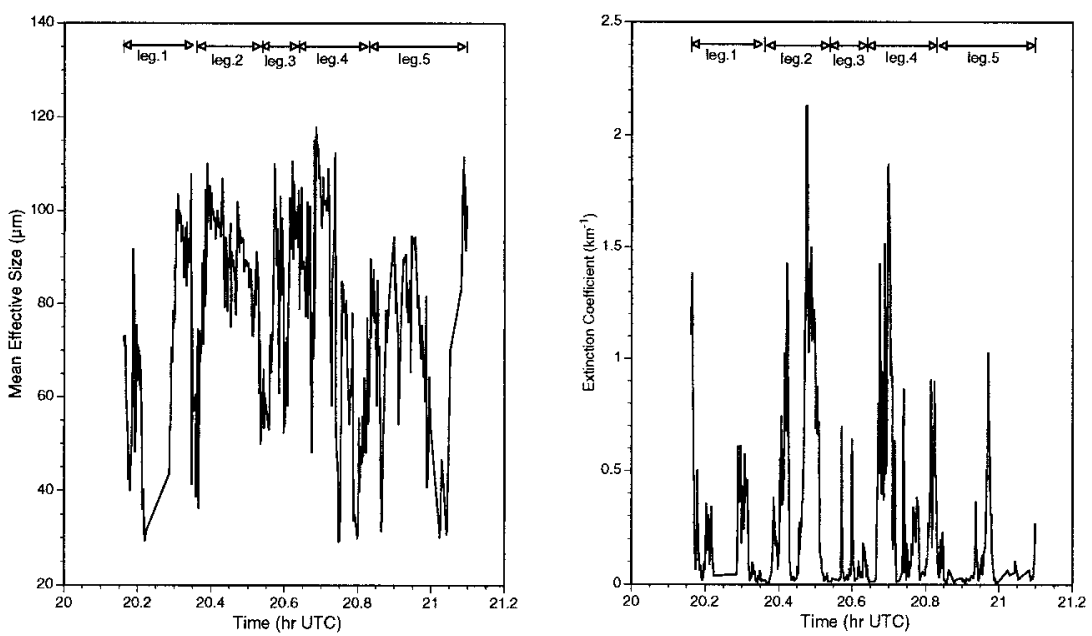

FIG. 12. The time series of (a) mean effective sizes and (b) extinction coefficients derived from $2 \mathrm{D}-\mathrm{C}$ probe data for the analysis period. 
FIRE-II-IFO (November 28, 1991)
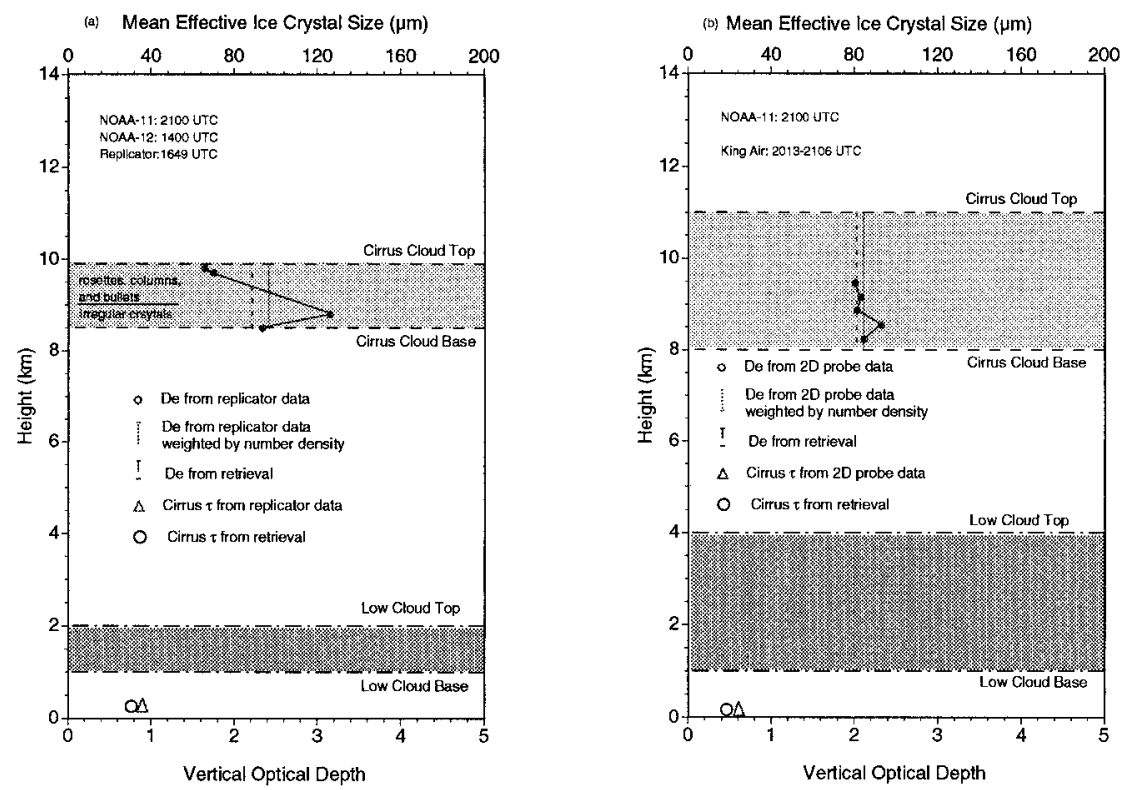

FIG. 13. (a) Display of the replicator-derived mean effective sizes at the selected height levels and their vertical average. The retrieved value is the average over a $1^{\circ} \times 1^{\circ}$ domain around Coffeyville. (b) Display of the mean effective sizes at five flight legs and their vertical averages. The retrieved value corresponds to the average of a rectangular domain around Coffeyville which encloses the King Air flight track.

parable to that of the temporal variation of the 2D-probe data. Moreover, the cirrus clouds that occurred on 28 November were optically thin. The reasonable agreement between the satellite-retrieved and in situ-determined cloud parameters shown in Fig. 13b for this thin cirrus case is quite encouraging.

\section{Summary and conclusions}

In this study, we have developed a numerical scheme that uses radiance data from AVHRR 3.7- $\mu \mathrm{m}$ and 10.9$\mu \mathrm{m}$ channels to infer cirrus cloud temperature, mean effective ice crystal size, and optical depth in multilayer cloud systems. This scheme is based on the solution of a set of algebraic equations derived from the theory of radiative transfer and parameterizations. In particular, we have developed a method to evaluate the upwelling radiance reaching the cirrus base, which is required for the solution on the basis of the statistics of low-cloud radiances. To apply this scheme to daytime retrievals, we have also developed an efficient program to remove the solar reflection part in the $3.7-\mu \mathrm{m}$ radiance.

For the validation of the retrieval program, the satellite, balloon-borne replicator and 2D-probe data have been analyzed for the two dates during FIRE-II-IFO, in which cirrus clouds overlay a layer of low stratus clouds. Comparisons with the ground-based and in situ measurements show that satellite-retrieved cloud temperatures are within the boundaries of the observed cirrus based on the replicator, radar, and lidar data. We also show that the retrieved mean effective sizes and optical depths are in general agreement with the values determined from the replicator and 2D-probe data. Because low clouds are generally optically thick and they shield effects of underlying surfaces, this retrieval program is expected to be applicable to most geographical areas, except polar regions where clouds are difficult to detect. It can also be fully automated because the algorithm is straightforward. Further validation efforts for the retrieval of cirrus cloud parameters with respect to spatial and temporal averages are required, as are additional cases involving multilayer cloud systems.

Acknowledgments. This research work was supported by NASA Grant NAG1-1719 and Air Force Geophysics Directorate Contract F19628-95-K-002. We thank B. Baum for providing satellite data and imageries, A. Heymsfield and L. Miloshevich for supplying replicator and 2D-probe data, and Y. Takano, P. Yang, and N. Rao for performing some of the calculations and graphing. Information on FIRE data summary was provided by K. Sassen.

\section{REFERENCES}

Baum, B. A, R. F. Arduini, B. A. Wielicki, P. Minnis, and S.-C. Tsay, 1994: Multilevel cloud retrieval using multispectral HIRS and 
AVHRR data: Nighttime oceanic analysis. J. Geophys. Res., 99, $5499-5514$

and Coauthors, 1995: Satellite remote sensing of multiple cloud layers. J. Atmos. Sci., 52, 4210-4230.

Fye, F. K., 1978: The AFGWC Automated Cloud Analysis Model. Tech Memo. 78-002, 97 pp. [Available from Air Force Global Weather Central, Offutt Air Force Base, NE, (ADA057176).]

Hahn, C. J., and Coauthors, 1982: Atlas of simultaneous occurrence of different cloud types over the ocean. NCAR Tech. Note, TN241+STR, 209 pp. [Available from National Center for Atmospheric Research, Boulder, CO 80307.]

— S. G. Warren, J. London, R. M. Chervin, and R. Jenne, 1984: Atlas of simultaneous occurrence of different cloud types over land. NCAR Tech. Note TN-241+STR, 216 pp. [Available from National Center for Atmospheric Research, Boulder, CO 80307.]

Heymsfield, A. J., and D. Baumgardner, 1985: Summary of a workshop on processing two-dimensional probe data. Bull. Amer. Meteor. Soc., 66, 437-440.

_ , and L. M. Miloshevich, 1993: Overview of microphysics and state parameter measurements from FIRE-II. FIRE cirrus results. Proc. FIRE Cirrus Science Conf., Breckenridge, CO, NASA, $1-4$.

Hu, Y. X., and K. Stamnes, 1993: An accurate parameterization of the radiative properties of water clouds suitable for use in climate models. J. Climate, 6, 728-742.
Mace, G. G., T. P. Ackerman, and E. E. Clothiaux, 1997: A study of composite cirrus morphology using data from a $94-\mathrm{GHz}$ radar and correlation with temperature and large-scale vertical motion. J. Geophys. Res., 102, 13581-13593.

Ou, S. C., K. N. Liou, W. M. Gooch, and Y. Takano, 1993: Remote sensing of cirrus cloud parameters using advanced very-high resolution radiometer 3.7- and 10.9- $\mu \mathrm{m}$ channels. Appl. Opt., 32, 2171-2180.

— and Coauthors, 1995: Remote sounding of cirrus cloud optical depths and ice crystal sizes from AVHRR data: Verification using FIRE-II-IFO measurements. J. Atmos. Sci., 52, 4143-4158.

—, K. N. Liou, and B. A. Baum, 1996: Detection of multilayer cirrus cloud systems using AVHRR data: Verification based on FIRE II IFO composite measurements. J. Appl. Meteor., 35, 178191.

Rao, N. X., S. C. Ou, and K. N. Liou, 1995: Removal of the solar component in AVHRR 3.7- $\mu \mathrm{m}$ radiances for the retrieval of cirrus cloud parameters. J. Appl. Meteor., 34, 482-499.

Rossow, W. B., and A. A. Lacis, 1990: Global, seasonal cloud variation from satellite radiance measurements. Part II: Cloud properties and radiative effects. J. Climate, 3, 1204-1253.

Takano, Y., and K. N. Liou, 1989: Radiative transfer in cirrus clouds. Part II: Theory and computation of multiple scattering in an anisotropic medium. J. Atmos. Sci., 46, 20-38.

Tian, L., and J. A. Curry, 1989: Cloud overlap statistics. J. Geophys. Res., 94, 9925-9935. 